\title{
Configurações
}

Revista de sociologia

\section{Joan Busfield (1996), Men, Women, and Madness: Understanding gender and mental disorder. New York: New York University Press}

\section{Thaiana Meneses Alves}

\section{(2) OpenEdition \\ Journals}

\section{Edição electrónica}

URL: http://journals.openedition.org/configuracoes/2649

DOI: 10.4000/configuracoes.2649

ISSN: 2182-7419

Editora

Centro de Investigação em Ciências Sociais

\section{Edição impressa}

Data de publição: 30 Junho 2015

Paginação: 89-93

ISBN: 1646-5075

ISSN: 1646-5075

\section{Refêrencia eletrónica}

Thaiana Meneses Alves, « Joan Busfield (1996), Men, Women, and Madness: Understanding gender and mental disorder. New York: New York University Press », Configurações [Online], 15 | 2015, posto online no dia 01 setembro 2015, consultado o 30 abril 2019. URL : http://journals.openedition.org/ configuracoes/2649; DOI : 10.4000/configuracoes.2649

Este documento foi criado de forma automática no dia 30 Abril 2019.

(c) CICS 


\title{
Joan Busfield (1996), Men, Women, and Madness: Understanding gender and mental disorder. New York: New York University Press
}

\author{
Thaiana Meneses Alves
}

1 Joan Busfield é uma socióloga e psicóloga inglesa, autora de publicações sobre doença mental e psiquiatria interessada em temáticas como doença mental, história da psiquiatria, indústria farmacêutica, políticas e serviços de saúde, relação entre gênero, doença mental e psiquiatria. Em Men, Women and Madness, Busfield analisa, com uma linguagem clara, as interconexões entre gênero e doença mental. Mais especificamente, examina a sobrerrepresentação de mulheres na população psiquiátrica nos dias atuais, mas interroga-se se este fato é inquestionável, visto que os dados epidemiológicos frequentemente são desagregados; explora como o gênero está imerso na construção de categorias de doença mental; e considera a extensão na qual fatores biológicos, psicológicos e sociais conduzem a diferenças entre homens e mulheres no que diz respeito à doença mental. A sua abordagem tem fundamento principalmente na sociologia e no feminismo, mas não é voltada exclusivamente para a comunidade sociológica. Men, Women and Madness é uma obra fundamental para uma variedade de profissionais, tais como médicos, psicólogos, assistentes sociais, acadêmicos de diversas áreas científicas ou para qualquer um que se interesse pela temática ou que tenha contato no dia a dia com pessoas com algum sofrimento mental. o livro combina uma exploração teórica e empírica da relação entre gênero e doença mental. $O$ exame teórico engloba abordagens sobre os conceitos de gênero e doença mental e sua interrelação. 0 material empírico provém de diversas fontes: estatísticas oficiais, pesquisas qualitativas, obras da psiquiatria, relatórios de políticas. A obra conta com doze capítulos distribuídos por Introdução, Parte I, Parte II e Conclusão.

2 Na Introdução, Busfield faz um resumo do conteúdo global do livro. No século XX, sob o impacto da segunda onda feminista, o gênero vem se tornando um objeto de análise 
dentro do campo da doença mental. Vários estudos feministas optaram por dar visibilidade às mulheres e tiveram como ponto de partida o exame da sobrerrepresentação feminina na população psiquiátrica.

3 Apesar da inquestionável e valiosa contribuição destes estudos, eles possuem algumas limitações. Primeiro, sustenta Busfield, o fato de abordarem exclusivamente as mulheres. Embora seja preciso evidenciá-las, não se podem ignorar as experiências dos homens nos serviços de saúde mental. Portanto, sua obra foca-se no "gênero" e não apenas nas mulheres ou no "gênero feminino". Segundo, a autora considera que grande parte desses estudos se apresenta relutante quanto à importância de analisar mais sistematicamente os dados epidemiológicos sobre gênero e doença mental, pois esses poderiam iluminar vários aspectos dessa relação. Terceiro, ainda que muitos estudos feministas tenham reivindicado que o gênero está embebido nas definições de loucura e doença mental, a maioria defende que a doença mental é uma forma de "desvio" social. Para Busfield, nem uma conceptualização médica que considere a doença mental como mera doença física, nem uma conceptualização sociológica que considere a doença mental como desvio são satisfatórias. Desta forma, propõe uma conceptualização em termos de irracionalidade e desrazão, o que inclui pistas para compreender a sua interação com o gênero. Quarto, salvo algumas exceções, os estudos feministas têm dado relativamente pouca atenção aos mecanismos que interligam gênero e construções das categorias de doença mental. Por fim, uma análise satisfatória sobre o fenômeno da doença mental requer o entrecruzamento da biologia, da psicologia, da estrutura social, dos recursos materiais e da cultura.

4 A Parte I do livro trata das construções da doença mental e da forma como o gênero está envolvido nessas construções. O ponto de partida é a análise da sobrerrepresentação feminina nas estatísticas de saúde mental. No capítulo 2, são exploradas as diferenças de gênero no cenário das doenças mentais mapeadas. Os dados epidemiológicos mostram que não é fácil ou consistente afirmar que a doença mental é predominantemente feminina, especialmente quando se confronta isto com o fato de uma "feminização da loucura" ter ocorrido a partir do século XIX, isto é, trata-se de um fenômeno relativamente "novo". No capítulo 3, a autora começa por tecer algumas considerações a respeito de sua perspectiva sobre o gênero: primeiro, as diferenças de gênero são um produto social e variam ao longo do tempo e do espaço. Além disso, diferenças de classe social, geração e etnia, por exemplo, são importantes para examinar homens e mulheres, homens entre si e mulheres entre si. Segundo, o gênero não deve ser visto de forma binária (masculino e feminino), mas como uma dimensão de graus contínuos de masculinidades e feminilidades. Terceiro, o gênero é um conceito relacional, pois é fundado a partir da comparação e do contraste, ou seja, masculinidade e feminilidade não podem ser completamente compreendidas sem fazer referência, explícita ou implicitamente, uma à outra. Quarto, o conceito de gênero sugere relações não apenas de "diferença", mas sobretudo de desigualdade (de poder) entre homens e mulheres. Por fim, com base em Raewyn Connell, a autora defende que o gênero é um linking concept, já que as relações genderizadas permeiam toda a vida social. Depois, Busfield considera um problema na discussão sobre gênero já identificado por autores/as feministas: a distinção radical entre sexo e gênero, que se traduz em concepções equivocadas, tais como a de uma distinção entre biológico e social, ou entre natureza e cultura; a ideia de que o gênero é independente do sexo; ou, ainda, a ideia de que o corpo é um objeto natural e passivo. A autora refere algumas teorizações sobre o gênero e tece argumentos sobre os 
seus limites e aportes para depois defender que uma teoria sobre o gênero deve ser baseada em fundamentos feministas, rejeitar o relativismo epistemológico, atentar tanto para as condições materiais e económicas, quanto para o domínio dos significados, dos símbolos e da cultura, realizar um exame sistemático das fontes e relações de poder, prestar atenção às especificidades culturais e históricas (materiais), não tratar o sistema de gênero como estando separado de outros sistemas, como o de classe. No capítulo 4, são analisadas diversas teorias sobre a doença mental. Busfield, tal como Foucault, propõe uma abordagem em termos de irracionalidade e desrazão que inclui pistas para compreender a sua interação com o gênero. No capítulo 5, são discutidos os problemas que podem surgir quando se examina a relação entre gênero e diagnóstico a partir de dados epidemiológicos. Dois tipos de dados são examinados: estatísticas sobre pacientes e pesquisas nas comunidades (pacient statistics e community surveys). Nenhum deles oferece medidas satisfatórias de diferenças de gênero a respeito da doença mental medicamente definida. É citado o caso da depressão, que, nas sociedades ocidentais, tem incidido mais sobre as mulheres, para mostrar que as diferenças de gênero não podem ser medidas de maneira simplista. Enquanto normalmente se atribuiria tal diferença à biologia, a variação cultural mostra que as próprias formas de medição têm valor limitado. Assim, os próprios dados epidemiológicos são produtos sociais. Convém, portanto, elencar os fatores sociais em ordem para entender a distribuição dos diagnósticos, incluindo as diferenças de gênero nos seus modos de expressão. No capítulo 6, a autora argumenta que o gênero está presente nas noções de loucura e de doença mental. Esta reivindicação tem uma base forte no trabalho de Phyllis Chesler, embora Busfield guarde diferenças teóricas com tal autora. Chesler é influenciada por antipsiquiatras como Szasz, Laing e Scheff, que entendem a loucura/doença mental como etiquetas e se referem ao exercício do controlo social através da psiquiatria, assim como pelo estruturo-funcionalismo na sua análise sobre os papéis sociais, incluindo os de gênero e doente, e a ideia da doença como "falha" no desempenho do papel. Chesler pressupõe que o gênero está intimamente ligado à loucura, na medida em que há expectativas em relação aos seus papéis: quando homens ou mulheres não se comportam de acordo com o que é socialmente esperado, são "etiquetados" de doentes. Mesmo que Busfield questione a teorização de Chesler em termos de "papéis de sexo", sugere que o ponto-chave e assertivo de sua análise é a forma como o gênero influencia a construção de categorias de doença mental. O gênero relacionado com noções de agência e racionalidade - invariavelmente atravessa as construções ofi ciais da psiquiatria (que, sendo supostamente neutras, podem acometer homens/mulheres de qualquer classe, etnia, tempo e lugar), a elaboração de casos normais (aqueles que descrevem características sociais/pessoais típicas de pacientes com vista a facilitar o diagnóstico) e a identificação de casos individuais (que consideram características da pessoa, incluindo o gênero). Todas são, portanto, inerentemente genderizadas e estão ligadas à regulação social do gênero. No capítulo 7 , a análise do gênero e da doença mental é desenvolvida dentro de um contexto mais amplo que engloba as mudanças nos serviços de saúde mental na Grã-Bretanha entre os séculos XIX e XX, entre eles: institutions for lunatics e outside of the asylum (ainda no século XIX) e community care (século XX). O balanço de gênero da população psiquiátrica durante tal período mostra como o acesso de homens e mulheres a estes serviços está associado às construções (genderizadas) das categorias "loucura" e "doença mental".

5 Na Parte II do livro, Busfield examina as diferenças relacionadas com a origem da doença mental em homens e mulheres a partir das construções sobre a doença e dos serviços de saúde mental. No capítulo 8, a autora destaca que se, por um lado, é um erro negligenciar 
o papel que a biologia tem sobre sentimentos, comportamentos e experiências relacionados com os processos mentais, por outro, a primazia dada à biologia oferece uma análise limitada das origens da doença mental. Além disso, as próprias teorias biologizantes sobre as diferenças entre homens e mulheres quanto às origens da doença são genderizadas, na medida em que fazem associações do tipo "mulheres/ vulnerabilidade" e "homens/agressividade". Busfield sugere, assim, o estudo da interação entre o biológico e o social. No capítulo 9, são analisados os limites e contributos das psicologias feministas a respeito do desenvolvimento psicológico de homens e mulheres. Por um lado, estes estudos ajudam a compreender as diferenças de gênero na expressão emocional. Suas limitações, no entanto, são claras: a tendência em generalizar o desenvolvimento psicológico humano que, quando aplicado às diferenças de gênero, conduz a essencialismos psíquicos; a tendência em atribuir muito peso ao "mundo interior" e pouco às situações e aos eventos "externos"; e, ainda, o foco nas patologias individuais em detrimento do exame das complexidades das sociedades em que as pessoas vivem. Teorias feministas que estudaram a anorexia nervosa, entretanto, avançaram nesse aspecto ao promover uma análise que destacou o desenvolvimento psicológico de homens e mulheres dentro de um contexto com características culturais e estruturais particulares, em sociedades e momentos específicos no tempo. O capítulo 10 faz a discussão sobre stress, doença mental e divisão sexual do trabalho. A noção de stress tem valor heurístico nas explicações sobre doença mental, mas não é possível fazer uma comparação quantitativa satisfatória dos diferentes níveis de stress entre homens e mulheres porque é difícil construir medidas de stress neutras em relação ao gênero. Considerar as situações estruturais específicas dos contextos masculinos e femininos e explorar suas ligações com a doença mental pode ser mais frutífero do que permanecer apenas pelos estudos epidemiológicos. São aqui analisadas duas situações: a divisão doméstica do trabalho e o trabalho feminino fora da esfera doméstica. No capítulo 11, são discutidas outras situações relacionadas com as vivências masculinas e femininas. $O$ foco é a violência, e o exame se dá sobre os traumas de guerra e o abuso sexual, mais comum para homens e mulheres, respectivamente, e as suas interfaces com o gênero, a doença mental e questões de poder e regulação social.

6 Busfield conclui que uma análise sobre gênero e doença mental possui implicações políticas. Se estamos conscientes da forma como o gênero (tal como a classe, a etnia, etc.) ajuda a estabelecer limites em torno da doença mental e a fazer juízos sobre casos individuais, precisamos de questionar continuamente quaisquer julgamentos sobre a doença, examinando se eles são apropriados e se estão relacionados com interesses individuais. Depois, é preciso olhar para além do corpo e da psique individual e atentar para a estrutura das vidas das pessoas, pois a saúde mental de homens e mulheres está ligada às condições sociais.

7 Mesmo não sendo uma obra "nova", Man, Women and Madness pode ser considerada uma das mais importantes no campo ainda pouco explorado da sociologia da saúde mental. 


\section{AUTOR}

THAIANA MENESES ALVES

Investigadora Integrada do Centro Interdisciplinar de Ciências Sociais - Polo UMinho

(CICS.NOVA.UMinho). Doutoranda em Sociologia pela Universidade do Minho. Bolseira da Fundação para a Ciência e a Tecnologia (Ref. ․ SFRH/BD/96628/2013). Endereço de correspondência: CICS.NOVA.UMinho, Campus de Gualtar 4710-057 Braga.

menesestahiana@gmail.com. 